\title{
Role of short-acting nitroglycerin in the management of ischemic heart disease
}

REVIEW

This article was published in the following Dove Press journal:

Drug Design, Development and Therapy

19 August 2015

Number of times this article has been viewed

\author{
William E Boden ${ }^{1-3}$ \\ Santosh K Padala ${ }^{1-3}$ \\ Katherine $\mathrm{P} \mathrm{Cabral}{ }^{4}$ \\ Ivo R Buschmann ${ }^{5}$ \\ Mandeep S Sidhul-3 \\ 'Department of Medicine, Division of \\ Cardiology, Albany Medical College, \\ ${ }^{2}$ Department of Medicine, Division of \\ Cardiology, Albany Stratton Veterans \\ Affairs Medical Center, ${ }^{3}$ Department \\ of Medicine, Division of Cardiology, \\ Albany Medical Center, ${ }^{4}$ Department \\ of Pharmacy, Albany College Pharmacy \\ and Health Sciences, Albany, NY, USA; \\ ${ }^{5}$ Department of Angiology, Medical \\ University of Brandenburg \& Charité, \\ Berlin, Germany
}

Correspondence: Mandeep S Sidhu Department of Medicine, Division of Cardiology, Albany Medical College, 47 New Scotland Avenue, Albany, NY 12208, USA

Tel +l 5182625076

Fax + I 5182625082

Email sidhum@mail.amc.edu

\begin{abstract}
Nitroglycerin is the oldest and most commonly prescribed short-acting anti-anginal agent; however, despite its long history of therapeutic usage, patient and health care provider education regarding the clinical benefits of the short-acting formulations in patients with angina remains under-appreciated. Nitrates predominantly induce vasodilation in large capacitance blood vessels, increase epicardial coronary arterial diameter and coronary collateral blood flow, and impair platelet aggregation. The potential for the prophylactic effect of short-acting nitrates remains an under-appreciated part of optimal medical therapy to reduce angina and decrease myocardial ischemia, thereby enhancing the quality of life. Short-acting nitroglycerin, administered either as a sublingual tablet or spray, can complement anti-anginal therapy as part of optimal medical therapy in patients with refractory and recurrent angina either with or without myocardial revascularization, and is most commonly used to provide rapid therapeutic relief of acute recurrent angina attacks. When administered prophylactically, both formulations increase angina-free walking time on treadmill testing, abolish or delay ST segment depression, and increase exercise tolerance. The sublingual spray formulation provides several clinical advantages compared to tablet formulations, including a lower incidence of headache and superiority to the sublingual tablet in terms of therapeutic action and time to onset, while the magnitude and duration of vasodilatory action appears to be comparable. Furthermore, the sublingual spray formulation may be advantageous to tablet preparations in patients with dry mouth. This review discusses the efficacy and utility of short-acting nitroglycerin (sublingual spray and tablet) therapy for both preventing and aborting an acute angina attack, thereby leading to an improved quality of life.
\end{abstract}

Keywords: angina, coronary artery disease, nitroglycerin spray, nitroglycerin sublingual tablets, optimal medical therapy

\section{Introduction}

According to the American Heart Association, approximately 15.4 million people $\geq 20$ years of age in the United States $(\sim 6.4 \%$ of overall prevalence of coronary heart disease [CHD]; 7.9\% men and 5.1\% women) in the year 2010 had ischemic heart disease (IHD). ${ }^{1}$ In 2009, the overall CHD death rate was 116.1 per 100,000 people. ${ }^{1}$ The death rates were 155.9 per 100,000 for white males and 181.1 per 100,000 for black males; for white females, the rate was 84.9 per 100,000, and for black females, it was 110.3 per $100,000 .{ }^{1}$ The Framingham study ${ }^{2}$ demonstrated $^{2}$ that the incidence of coronary events increases significantly with age. For instance, the overall incidence of CHD in subjects between ages 65 and 95 years increases twofold in men and threefold in women compared with that in individuals 35 to 64 years of age. Moreover, the incidence rates indicate a significant variation by sex, where men typically exhibit an earlier onset ( $~ 10$ years) of symptomatic CHD than women. $\mathrm{CHD}$ in women younger than 75 years of age presents more frequently as angina than 
as myocardial infarction (MI), and not infrequently, women will present with atypical anginal symptoms such as dyspnea, nausea, or excessive fatigue. ${ }^{3,4}$ Notably, angina tends to be isolated in $80 \%$ of these patients; however, in $66 \%$ of men, angina appears after an MI. Overall, MI is prevalent among men in all age groups, and only $20 \%$ of cases are preceded by angina. ${ }^{4}$ In terms of mortality, there were 7,249,000 IHDrelated deaths reported worldwide in 2008, accounting for $12.7 \%$ of all global deaths. ${ }^{5}$

Based on guidelines, ${ }^{6,7}$ health care providers use shortacting nitroglycerin for relief of acute angina only. However, its prophylactic use as part of a comprehensive management approach toward optimal medical therapy (OMT) and lifestyle modification is under-appreciated. Despite current treatment efforts, mortality due to IHD continues to increase worldwide because of the combined effects of population growth, aging, and emergence of an increase in comorbidities such as hypertension, dyslipidemia, diabetes mellitus, and obesity. The total mortality burden remains high, as the effect of age on IHD mortality is very strong in high-income countries with a large aging population. Furthermore, larger populations and high age-specific death rates for IHD in low- and middle-income countries, as well as in emerging societies, contribute toward a majority of global IHD-related deaths and an anticipated global IHD epidemic in the near future. ${ }^{5}$

\section{Nitroglycerin}

Nitroglycerin was first formulated as a short-acting nitrate preparation for clinical use in 1879, and is the oldest and most commonly prescribed short-acting anti-anginal agent. ${ }^{8,9}$ Nitrates are now available in many delivery forms, from long-acting oral preparations, to cutaneous ointments, longacting transdermal patches, and intravenous formulations. This review will focus solely on short-acting, sublingual nitrates, which are the most under-appreciated and possibly underutilized nitrates.

Despite being in clinical use since 1879 , there remains an important need to educate both patients and health care providers on the various benefits of short-acting nitrates, particularly sublingual nitroglycerin, administered as sublingual tablets or spray ${ }^{10}$ in patients with angina. In the majority of patients with stable ischemic heart disease (SIHD), long-acting nitrates are used as part of OMT to reduce the risk of cardiovascular morbidity (notably angina and myocardial ischemia) and thus, to enhance the quality of life by reducing symptoms ${ }^{8}$ and improving exercise capacity. ${ }^{11-13}$ Under-appreciated is the fact that nitrates play an important role in the prophylactic treatment of angina caused by shortterm physical or emotional stress. Therefore, nitrates can be integrated into a comprehensive management approach toward OMT and lifestyle modification as a prophylactic measure and should be included as part of an overall treatment plan when advising patients on undertaking exercise or strenuous physical activity. ${ }^{8}$ Similarly, prophylactic nitroglycerin should be used as part of an overall structured cardiac rehabilitation program for secondary prevention in patients with SIHD.

\section{Mechanism of action of nitroglycerin Effect on endothelial function}

Endothelium is the innermost lining of the blood vessels; therefore, it is sensitive to circulatory mediators that contract and relax the blood vessels. Furthermore, a healthy endothelium is also able to produce mediators to promote endothelial function and maintain the tone of the blood vessels. Endothelial dysfunction decreases the production (or enhances inactivation) of the endothelium-derived relaxing factor (EDRF), which is identified as nitric oxide (NO). Organic nitrates such as nitroglycerin are converted to NO and have the ability to replenish deficient levels of EDRF and NO in patients with coronary artery disease (CAD). ${ }^{14}$ Improvement of endothelial function leads to CHD risk reduction, ${ }^{14}$ as NO released from endothelial cells activates soluble guanylate cyclase, thereby increasing the level of intracellular cyclic guanosine monophosphate (cGMP) and thus causing vasorelaxation, platelet disaggregation, and prevention of platelet adhesion (Figure 1). In addition, this protective pathway of NO-mediated endothelial effects reduces the effects of vasoconstrictor substances. Therefore, in patients with CAD, exogenous nitrate administration substitutes the effects of the impaired activity of the endothelial 1-arginine/NO pathway. ${ }^{15}$

Furthermore, it is notable that exogenous and endogenous nitrates differ in several aspects. Endothelium-derived NO is produced locally (autocrine release) and is not a circulating hormone. By contrast, therapeutic nitrates (administered orally or systemically) primarily act in a systemic manner and do not necessarily induce the same physiologic effects. Although the endothelium is predominantly morphologically intact in atherosclerotic blood vessels (except in advanced disease stages and at sites of plaque rupture), the endotheliumdependent relaxation is reduced in atherosclerotic human coronary arteries in response to acetylcholine, histamine, substance $\mathrm{P}$, and aggregating platelets. The decrease in endothelium-dependent relaxation in atherosclerosis is 


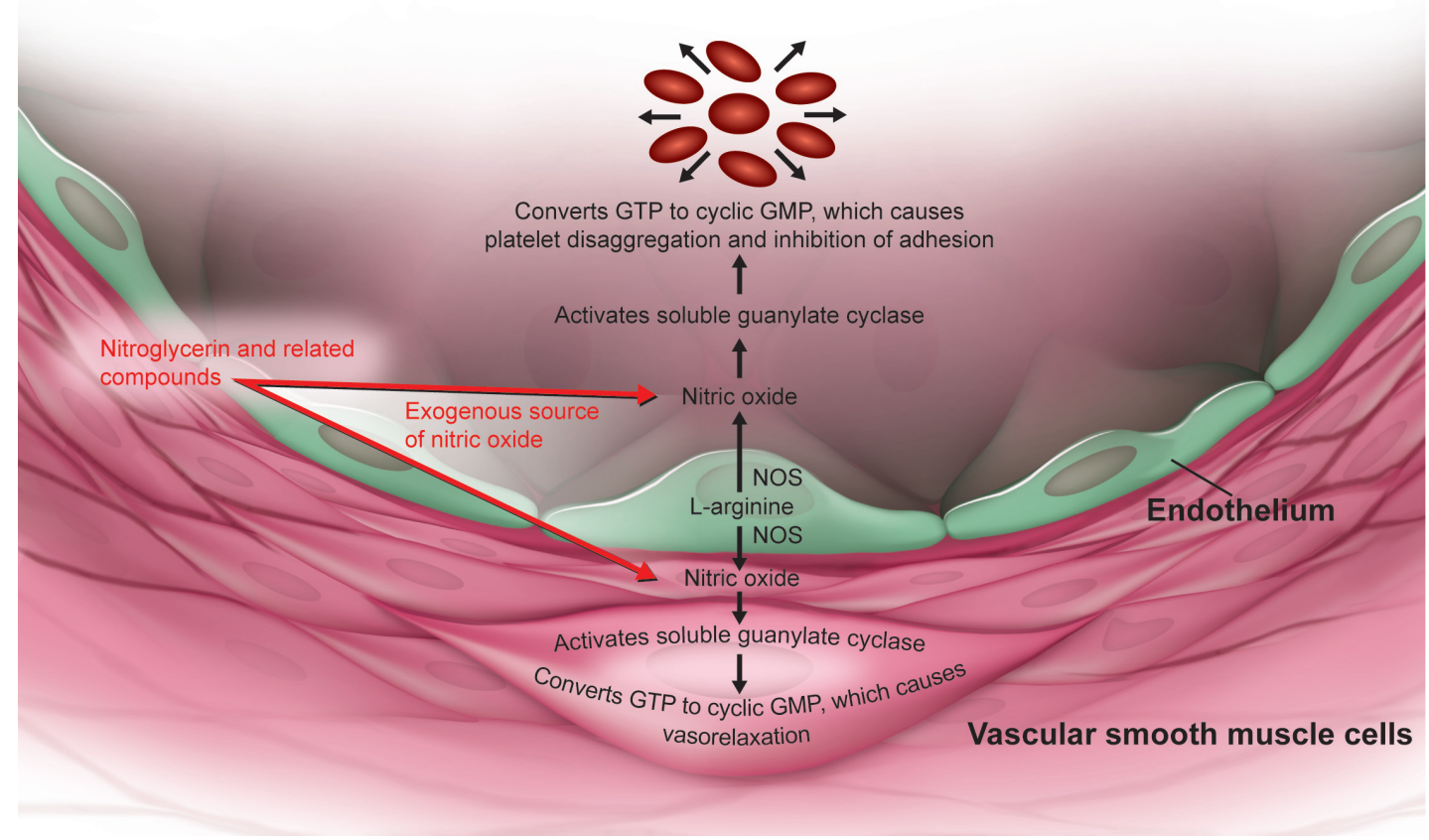

Figure I Effect of exogenous and endogenous sources of nitric oxide.

Abbreviations: GMP, guanosine monophosphate; GTP, guanosine triphosphate; NOS, nitric oxide synthase.

primarily related to a decrease in endothelium-derived NO. Although the sensitivity to nitroglycerin can be reduced particularly in more advanced lesions, its maximal response is well maintained overall, suggesting that a decreased endothelial-dependent relaxation is related to a decreased release of endothelial NO. Furthermore, the mechanism with which nitrates such as nitroglycerin release NO is prone to tachyphylaxis. In contrast, 1-arginine-derived endogenous nitrates do not develop tolerance.$^{15}$ Exogenous nitrates are endothelium-independent vasodilators in that they are not dependent on intact functioning endothelial layer for their conversion to $\mathrm{NO}$ and vasodilator properties. ${ }^{16}$ In fact, the action of exogenous nitrates is particularly augmented in blood vessels with a low basal production of $\mathrm{NO}$, such as atherosclerotic coronary arteries; therefore, nitrates play an important role in such patients. ${ }^{15}$

\section{Effects of nitrates on coronary and peripheral circulation}

Nitroglycerin alleviates anginal symptoms by decreasing myocardial oxygen consumption as a function of: 1) reducing preload, systolic wall stress, and afterload; 2) restoring flow imbalances; dilating coronary arteries (pre-stenotic, stenotic, and post-stenotic segments); 3) increasing subendocardial myocardial perfusion by lowering left ventricular diastolic pressure; 4) preventing coronary artery vasospasm; and
5) acting as a physiologic substitute for EDRF in endothelial dysfunction. ${ }^{14,17}$ Due to the potent venodilatory effects on capacitance vessels, nitrates reduce left ventricular filling pressures and preload, which may be a very useful therapeutic adjunct clinically, in patients with heart failure. ${ }^{17}$

\section{Effect on collateral blood flow}

Nitrates produce vasodilation, with predominant venous effects on large capacitance vessels. They also increase coronary collateral circulation, increase aortic compliance and conductance, and blood flow to ischemic areas of the myocardium. ${ }^{18-20}$ Fam and McGregor observed that the heterogeneity of coronary flow was dependent on different sites of action of various coronary artery vasodilators. ${ }^{21,22}$ Their work demonstrated that nitroglycerin, when administered intravenously, selectively relaxes the epicardial conductance vessels, thus facilitating flow through collateral arteries to zones of myocardial ischemia. ${ }^{21,22}$ This led to the notion that nitroglycerin may exert part of its anti-anginal effect by preferentially directing blood flow to the ischemic myocardium. Follow-up studies have evaluated this hypothesis by using washout rates of intra-myocardial Xenon-133 $\left({ }^{133} \mathrm{Xe}\right)$ in anesthetized open-chest hearts, ${ }^{23}$ computer-assisted measurements of luminal stenosis, ${ }^{24,25}$ and positron emission tomography with $\left({ }^{13} \mathrm{~N}\right)$ ammonia as a flow tracer. ${ }^{18}$ Sublingual nitroglycerin can enhance perfusion in areas of the human 
myocardium supplied by coronary arteries with significant luminal stenosis, particularly the collateral vessels. Using the ${ }^{133} \mathrm{Xe}$ washout technique in 31 patients in a stress-free resting state, Cohn et al demonstrated an improvement in regional myocardial blood flow (MBF) after sublingual nitroglycerin, most likely mediated through physiologically normally functioning collateral vasculature. ${ }^{26}$

\section{Effect on platelets}

Organic nitrates are metabolized to NO (or its S-nitrosothiol congener), which is a potent activator of platelet guanylate cyclase. Activation of guanylate cyclase increases levels of platelet cGMP and leads to decreased fibrinogen binding to the glycoprotein IIb/IIIa receptor. As fibrinogen binding is critically essential for platelet aggregation, its inhibition leads to impairment of platelet function. ${ }^{27}$ Further, Diodati et al evaluated the effect of a nitroglycerin infusion on platelet aggregation response to adenosine diphosphate and to thrombin in patients with unstable angina and acute MI. ${ }^{28}$ Platelet response before, during, and after a 45-minute infusion of nitroglycerin showed $>50 \%$ inhibition of platelet aggregation, which returned to normal 15 minutes after nitroglycerin discontinuation. ${ }^{28}$ As platelet aggregation is a causal factor in acute coronary syndromes, inhibition of platelets by nitrates may suggest an additional potential mechanism to improve perfusion to ischemic myocardium. ${ }^{27}$

\section{Effect on flow-mediated dilation}

Furthermore, the effect of nitroglycerin on pulmonary artery diastolic pressure (PAPd), and peripheral arterial (a/b ratio of the finger pulse wave plethysmography) hemodynamics is such that the mean time courses of a decrease in PAPd and an increase in the $\mathrm{a} / \mathrm{b}$ ratio of the finger pulse curve are mirror images. Thus, there is a strong correlation between the two after nitroglycerin administration. Therefore, the onset of effect and time to peak effect on PAPd can easily be predicted by finger plethysmography. ${ }^{29-31}$

Tadamura et al compared the effects of nitroglycerin spray on MBF and coronary vascular resistance (CVR) in 23 patients with CAD and eleven healthy volunteers. Nitroglycerin spray did not change the global MBF in either group, but did preferentially reduce CVR in the viable myocardium with ischemia. After nitroglycerin spray, the tracer uptake in the ischemic myocardium was relatively increased compared with that in the nonviable and non-ischemic myocardium. ${ }^{32}$

Overall, exogenous nitrates including nitroglycerin are endothelium-independent vasodilators, and their conversion to NO is particularly augmented in atherosclerotic coronary arteries with low basal production of NO. ${ }^{15,16}$ In addition, nitrates alleviate anginal symptoms by directly influencing the coronary arteries, coronary collateral circulation, aortic compliance and conductance, and blood flow to ischemic areas of the myocardium. ${ }^{18-20}$ They also help reduce preload in patients with heart failure. ${ }^{17}$

\section{Short-acting nitroglycerin in angina}

Sublingual nitroglycerin should be considered as first-line therapy for the treatment of angina in patients with suspected unstable angina or IHD who are either being observed for rule-out MI management protocols, have been discharged from a hospital emergency department, or have been hospitalized with angina pectoris, with or without acute MI. Moreover, short-acting nitroglycerin can be used to supplement long-acting nitrates, as part of OMT, to prevent recurrent angina attacks. Atherosclerotic lesions in one or more coronary arteries limit segmental coronary blood flow during exercise or emotional stress. The corresponding increase in myocardial oxygen demand cannot be met by segmental coronary blood flow, and may lead to myocardial ischemia and angina pectoris. ${ }^{33}$ When administered prophylactically, nitroglycerin increases angina-free walking time on treadmill tests, abolishes or delays ST segment depression, and increases exercise tolerance. ${ }^{11,34}$ Prophylactic use of nitroglycerin spray has been shown to increase exercise performance in IHD patients by improving self-confidence and self-assurance by alleviating fear of another angina attack during physical activity. ${ }^{12}$

In the Clinical Outcomes Utilizing Revascularization and Aggressive Drug Evaluation (COURAGE) trial, 60\%-65\% of patients received combinations of short- and long-acting nitrates. ${ }^{35,36}$ The COURAGE trial evaluated 2,287 patients with documented myocardial ischemia and angiographically confirmed single or multivessel CAD. Along with lifestyle modifications, these patients were randomized to a strategy of percutaneous coronary intervention (PCI) plus OMT, or OMT alone. ${ }^{37}$ The COURAGE trial found no incremental clinical benefit from an initial strategy of PCI plus OMT in reducing the composite primary outcome of death, or MI over OMT alone, during a median follow-up period of 4.6 years. ${ }^{36}$ Moreover, the addition of short-acting sublingual nitrates can complement other anti-anginal medications in patients with refractory and recurrent angina, including those who have already undergone either a percutaneous or a surgical revascularization procedure. ${ }^{13}$ A comparison of short- and long-acting nitrates is presented in Table 1. 
Table I Comparison of short- and long-acting nitrates

\begin{tabular}{|c|c|c|}
\hline & Short-acting nitrates & Long-acting nitrates \\
\hline Absorption & $\begin{array}{l}\text { Rapidly absorbed; therefore, formulations } \\
\text { of nitroglycerin are the mainstay for rapid } \\
\text { relief of angina. }\end{array}$ & Used for long-term prophylaxis of angina. \\
\hline \multirow[t]{2}{*}{ Prophylaxis } & $\begin{array}{l}\text { Prophylaxis for anticipated short-term } \\
\text { physical and emotional stress. }\end{array}$ & $\begin{array}{l}\text { Prophylaxis improves physical and emotional stress; } \\
\text { however, it is subject to eventual development of tolerance. } \\
\text { Transdermal nitrate formulations cause a decrease in exercise } \\
\text { duration prior to retreatment (often referred to as time-zero } \\
\text { effect). }\end{array}$ \\
\hline & $\begin{array}{l}\text { Not suitable for continuous or prolonged } \\
\text { antianginal prophylaxis. }\end{array}$ & Suitable for continuous or prolonged antianginal prophylaxis. \\
\hline Tolerance & $\begin{array}{l}\text { Intermittent use is not associated with the } \\
\text { development of tolerance. }\end{array}$ & $\begin{array}{l}\text { Multi-dose regimens lead to development of tolerance. } \\
\text { Appropriate regimens required with nitrate free intervals. } \\
\text { Implementing a nitrate-free period or a low nitrate level at night } \\
\text { may offer the most reliable means to maintain effectiveness. }\end{array}$ \\
\hline $\begin{array}{l}\text { Concomitant use with } \\
\text { other antianginal } \\
\text { medications }\end{array}$ & $\begin{array}{l}\text { Added benefit with other antianginal medications. } \\
\text { Short-acting nitrates may also be used to supplement } \\
\text { long-acting nitrates when patients experience acute } \\
\text { attacks. }\end{array}$ & $\begin{array}{l}\text { Added benefit with other antianginal medications. } \\
\text { Long-acting nitrates may be used to extend the duration of } \\
\text { action of the short-acting forms. }\end{array}$ \\
\hline Side effects & $\begin{array}{l}\text { Side-effects similar to long-acting nitrates but not } \\
\text { subject to tolerance. } \\
\text { No increase in risk of angina with optimal dosing. }\end{array}$ & $\begin{array}{l}\text { Side-effects similar to short acting nitrates but vary with } \\
\text { development of tolerance. } \\
\text { Increased risk of angina at rest during nitrate-free periods with } \\
\text { transdermal nitrate formulations, as has a decrease in exercise } \\
\text { duration prior to retreatment (often referred to as time-zero } \\
\text { effect). }\end{array}$ \\
\hline Secondary prevention & $\begin{array}{l}\text { Plays an integral part in secondary prevention which } \\
\text { is an essential component of coronary artery disease } \\
\text { management. }\end{array}$ & $\begin{array}{l}\text { Plays an integral part in secondary prevention which is an } \\
\text { essential component of coronary artery disease management. }\end{array}$ \\
\hline
\end{tabular}

\section{Current guidelines for treatment of angina}

The European Society of Cardiology ${ }^{6}$ and American College of Cardiology/American Heart Association guidelines routinely recommend short acting nitrates for use in the management of $\mathrm{SIHD}^{7}$, unstable angina (UA) or non-ST elevation MI (NSTEMI). ${ }^{38}$ Among short-acting nitrates, sublingual nitroglycerin tablets are the standard initial therapy for effort-induced angina in the US, while sublingual nitroglycerin spray is favored in most European countries as the preferred short-acting formulation. Nitroglycerin can be used prophylactically when angina is anticipated, such as with activity after a meal, emotional stress, sexual activity (though this should not be used concomitantly in patients taking phosphodiesterase inhibitors [see the "Safety, side effects, tolerability, and costs" section]), appropriate pharmacotherapy (eg, acetylsalicylic acid, sublingual nitroglycerin, and/ or $\beta$-blockers) while awaiting results of a stress test, and in colder weather ${ }^{6,38}$ which leads to vasoconstriction to mitigate heat loss. ${ }^{39}$ Since short-acting nitroglycerin is rapid acting, the spray or sublingual tablets can provide effective symptom relief in attacks of angina pectoris. ${ }^{6,38}$ In SIHD patients, sublingual nitroglycerin tablets or spray are recommended for immediate relief of angina (Class I, Level of Evidence, B). ${ }^{67}$ Most patients respond within 5 minutes of taking one to two sublingual dose(s) of $0.3-0.6 \mathrm{mg}$ each. Nitroglycerin spray is available in a $0.4 \mathrm{mg}$ metered dose canister that typically dispenses 200 doses. The tablets should be placed under the tongue and not swallowed. If the spray is used, it should be applied to the tongue and not swallowed or inhaled. If additional doses are necessary, they should be taken at 5-minute intervals for a maximum dose of $\leq 1.2 \mathrm{mg}$ within 15 minutes. During this timeframe, if relief does not occur, the patient should seek immediate medical attention.

The combination of a $\beta$-blocker with a nitrate could be an additive combination in patients with SIHD. However, abrupt $\beta$-blocker withdrawal should be avoided, because heightened $\beta$-receptor density and sensitivity can result in a rebound phenomenon associated with an increased risk for acute MI and sudden cardiac death. If withdrawal is necessary, $\beta$-blockers should be tapered over a $1-3$-week period, with consideration given to use of sublingual nitroglycerin or substitution with a non-dihydropyridine calcium channel blocker during withdrawal period. ${ }^{7}$ 
Further details, including recommendations for nitroglycerin sublingual tablets or spray for patients with suspected UA, or UA/NSTEMI with ongoing ischemic discomfort, and all post-UA/NSTEMI patients, are provided in Table S1. ${ }^{38}$ Differences in use of nitroglycerin across guidelines are presented in Table 2.

\section{Overview of sublingual nitroglycerin agents \\ Formulation comparative analysis}

Optimal utilization and efficacy of nitrate therapy requires an understanding of the properties that vary with different formulations to be able to select the most appropriate formulation for each clinical scenario. These properties include time to onset of action, duration of activity, stability/ potency, development of tolerance, convenience, adherence, cost, and patient preference. ${ }^{8}$ Nitroglycerin spray has been shown to be effective in patients with SIHD on OMT, and it may be beneficial for those with persistent angina after revascularization. ${ }^{13}$ Furthermore, in an 8-week comparative, non-blinded study, (410 patients, nitroglycerin spray; 387 patients, $500 \mu \mathrm{g}$ nitroglycerin sublingual tablets) data were analyzed to compare the two treatments between older patients ( $\geq 65$ years of age) and younger patients ( $<65$ years of age). This study was performed in a general internal medicine practice setting, was oral questionnaire-based, and did not define angina class, severity, or frequency. The results demonstrated that nitroglycerin lingual spray is a suitable alternative to sublingual tablets, irrespective of patient age. Also, the side effect of headache was less in the

Table 2 Recommendations for nitroglycerin across guidelines

\begin{tabular}{|c|c|c|}
\hline National Heart Foundation & National Institute for Health and & Canadian Cardiovascular Society ${ }^{60}$ \\
\hline of Australia ${ }^{58}$ & Clinical Excellence ${ }^{59}$ & 1997: Consensus conference on the evaluation \\
\hline $\begin{array}{l}\text { Guidelines for the management of acute } \\
\text { coronary syndromes } 2006 \text {. }\end{array}$ & $\begin{array}{l}\text { NICE clinical guideline I } 26 \text { Management } \\
\text { of stable angina. }\end{array}$ & and management of chronic ischemic heart disease. \\
\hline
\end{tabular}

coronary syndromes 2006.

Acute management of chest pain

Getting to hospital

Chest discomfort at rest or for a prolonged period (more than 10 minutes, not relieved by sublingual nitrates), recurrent chest discomfort, or discomfort associated with syncope or acute heart failure are considered medical emergencies. Other presentations of acute coronary syndrome may include back, neck, arm or epigastric pain, chest tightness, dyspnea, diaphoresis, nausea and vomiting. Very atypical pain, including sharp and pleuritic pain, is more common in women, people with diabetes and older people. People experiencing such symptoms should seek help promptly and activate emergency medical services to enable transport to the nearest appropriate health care facility for urgent assessment (grade D recommendation) [Grade D = No evidence available - panel consensus judgment].

Actions in transit

Aspirin (300 mg) should be given unless already taken or contraindicated (grade $A$ recommendation), and should preferably be given early (eg, by emergency or ambulance personnel) (grade D recommendation). Oxygen should also be given (grade D recommendation). Glyceryl trinitrate and intravenous morphine should be given as required. of stable angina.

Issued: July $201 \mathrm{I}$.

Last modified: December 2012.

General principles for treating people with stable angina

Do not exclude people with stable angina from treatment based on their age alone.

Do not investigate or treat symptoms of stable angina differently in men and women or in different ethnic groups.

Preventing and treating episodes of angina Offer a short-acting nitrate for preventing and treating episodes of angina.

Advise people with stable angina:

- How to administer the short-acting nitrate

- To use short-acting nitrate immediately before any planned exercise or exertion

- That side effects such as flushing, headache, and light-headedness may occur

- To sit down or find something to hold on to if feeling light-headed.

When a short-acting nitrate is being used to treat episodes of angina, advise people:

- To repeat the dose after 5 minutes if the pain has not subsided.

\author{
Medical therapy for chronic ischemic \\ heart disease \\ Nitrate therapy \\ Nitroglycerin in various forms is used in \\ virtually all patients with symptomatic ischemic \\ heart disease. Sublingual nitroglycerin is highly \\ effective in shortening or terminating episodes \\ of angina on exertion or at rest. It is highly \\ effective if used prophylactically before activities \\ that the patient has learned may bring on angina. \\ - Patients with angina should use sublingual tablets \\ or spray for pain and prophylaxis (grade A, class I) \\ - Nitrospray is as effective as tablets (grade B, \\ class I).
}


spray group, but more spray-treated patients reported taste disturbance. ${ }^{40}$

Several other potential advantages surface when comparing the sublingual spray formulation to the tablets. By using high-resolution brachial artery ultrasound, Ducharme et al compared the brachial vasodilatory response to two nitroglycerin preparations in normal volunteers by measuring the rapidity of onset and the magnitude and duration of effects. ${ }^{41}$ The sublingual tablets induced significant brachial artery dilation, which peaked at 3 minutes, and was no longer significant at 10 minutes. The lingual spray had a faster onset of action, as significant vasodilation was observed at 2 minutes, peaked at 3 minutes, and was significantly sustained at 15 minutes. ${ }^{41}$

A significant advantage is that nitroglycerin sublingual spray does not require adequate saliva production for full dissolution, as the sublingual tablets do. ${ }^{41}$ Tablet dissolution takes $15-90$ seconds, ${ }^{42}$ requires adequate saliva, and thus, varies from one person to another. This difference in terms of bioavailability may be more conspicuous in the elderly because of dentures or dryness of the mouth. ${ }^{41}$ Therefore, when oral secretions are decreased, the increased speed of onset, magnitude, and duration of vasodilatory actions of the sublingual spray may be advantageous. ${ }^{41,43}$

Pharmacokinetics and pharmacodynamics of short-acting nitroglycerin preparations are presented in Table 3.

\section{Safety, adverse effects, tolerability, and costs}

Nitroglycerin is generally well tolerated, with the most common adverse drug effects being dose-dependent headache, flushing, and dizziness due to its vasodilatory effects. ${ }^{44}$ In a dose ranging study, the incidence of headache was dose dependent, increasing from 0 with placebo to $3(6 \%), 5$ $(10 \%), 6(12 \%)$, and $8(16 \%)$ after $0.2,0.4,0.8$, and $1.6 \mathrm{mg}$ doses of nitroglycerin spray, respectively. No treatmentrelated serious adverse events were reported. ${ }^{13}$ In a primary care practice, oral questionnaire-based study, Vandenburg et al evaluated 352 patients with a clinical history of angina randomized to receive either the nitroglycerin spray or tablet using a predetermined schedule. Compared with tablets, the reported headaches were less in number and milder in intensity with spray. The tolerability was similar between spray and sublingual tablet formulations. ${ }^{45}$ Although the exact incidence of headache with sublingual nitroglycerin is not known, a small fraction of patients with stable angina experience incapacitating headaches and refuse to take sublingual nitroglycerin. It is postulated that NO is involved because of the effect of NO-donor nitroglycerin in the pathophysiology of migraine. ${ }^{46}$ This has been evaluated in the nitroglycerin headache models, which explore pathophysiologic mechanism of migraine pain and cluster headache. ${ }^{47}$ Although no significant difference in the nature of adverse events exists between the two formulations, patients on nitroglycerin spray do occasionally report taste disturbance. ${ }^{40}$

It is imperative that patients are carefully instructed regarding the use of short-acting nitroglycerin before administration. ${ }^{44}$ Overdosing on sublingual nitroglycerin may cause postural hypotension and reflex cardiac sympathetic activation with tachycardia, leading to paradoxical (or rebound) angina. Furthermore, an angina attack that does

Table 3 Pharmacokinetics, pharmacodynamics, safety, and tolerability of nitroglycerin preparations

\begin{tabular}{|c|c|c|c|c|}
\hline $\begin{array}{l}\text { Nitroglycerin } \\
\text { route }\end{array}$ & $\begin{array}{l}\text { Usual dose (daily } \\
\text { unless mentioned) }\end{array}$ & $\begin{array}{l}\text { Onset } \\
\text { of action, } \\
\text { minutes }\end{array}$ & $\begin{array}{l}\text { Duration, } \\
\text { minutes }\end{array}$ & Side effects and tolerability \\
\hline Sublingual tablet & $\begin{array}{l}0.3 \text { to } 0.6 \mathrm{mg} \text {, can be } \\
\text { repeated every } 5 \text { minutes } \\
\text { up to a maximum of three } \\
\text { tablets or up to } 1.5 \mathrm{mg} \text { as } \\
\text { needed }\end{array}$ & 2 to 5 & 10 to 30 & $\begin{array}{l}\text { Headache } \\
\text { Flushing } \\
\text { Dizziness } \\
\text { Overdose may lead to postural hypotension and paradoxical angina. } \\
\text { Avoid with the concomitant use of phosphodiesterase type } 5 \\
\text { inhibitors and volume depleted patients (eg, diuretics). } \\
\text { Cautious use in patients with hypotension and severe valvular stenosis. } \\
\text { Contraindicated in patients allergic to nitrates and generally not } \\
\text { prescribed in hypertrophic cardiomyopathy. }\end{array}$ \\
\hline Spray/mist/aerosol & $\begin{array}{l}0.4 \mathrm{mg} \text {, I to } 2 \text { sprays as } \\
\text { needed, up to } 3 \text { doses } \\
5 \text { minutes apart }\end{array}$ & 2 to 5 & 10 to 30 & $\begin{array}{l}\text { Lower incidence and intensity of headache. } \\
\text { Flushing } \\
\text { Dizziness } \\
\text { Avoid with the concomitant use of phosphodiesterase type } 5 \\
\text { inhibitors and volume depleted patients (eg, diuretics). } \\
\text { Cautious use in patients with hypotension and severe valvular stenosis. } \\
\text { Contraindicated in patients allergic to nitrates and generally not } \\
\text { prescribed in hypertrophic cardiomyopathy. }\end{array}$ \\
\hline
\end{tabular}


not respond to short-acting nitroglycerin (generally defined as a lack of improvement in chest discomfort following up to three short-acting nitrates every 5 minutes) should be regarded as consistent with a possible acute MI requiring immediate medical attention and evaluation. ${ }^{44}$

The development of tolerance is not uncommon with long-acting nitrates and includes an early pseudo-tolerance and a late vascular tolerance phenomena. Pseudo-tolerance involves early counter-regulatory responses such as activation of vasoconstrictor signals and intravascular volume expansion. Vascular tolerance (eg, loss of nitrovasodilator responsiveness) is induced after long-term treatment and involves intrinsic vascular changes. The postulated mechanisms include increased vascular superoxide production and an increased sensitivity to vasoconstrictors secondary to a tonic activation of protein kinase C. Other more recently proposed mechanisms include inhibition of mitochondrial aldehyde dehydrogenase, which causes bioactivation of nitroglycerin, and a new source of reactive oxygen species from the mitochondria. ${ }^{48}$ Therefore, tolerance is less likely with short-acting nitrates, and providers should not restrict nitrate use due to fear of tolerance.

Additionally, there are several drug interactions that warrant caution and education. Sublingual nitroglycerin use should be avoided with the concomitant use of phosphodiesterase type 5 inhibitors such as sildenafil, vardenafil, and tadalafil. Combined use of these agents can cause dizziness or systemic hypotension accompanied by paradoxical bradycardia, leading to increased angina pectoris. Caution is also warranted in administering sublingual nitroglycerin to patients with hypotension (or borderline systolic blood pressures of $<100 \mathrm{mmHg}$ ), those on concomitant diuretics, and during the early time period following acute MI. Its use is contraindicated in patients allergic to organic nitrates, and it is generally not prescribed in patients with hypertrophic cardiomyopathy (particularly true with the use of long-acting nitrates in elderly patients), as it can aggravate angina and precipitate a decline in preload and stroke volume, leading to hypotension. . $^{8,49}, 50$ Caution is also advised in administering nitrates to patients with severe valvular aortic stenosis in whom a decrease in systemic vascular resistance in the setting of a high-pressure gradient and decreased aortic valve orifice area may be associated with arterial hypotension and/or syncope. ${ }^{51-53}$

\section{Implications}

Short-acting nitroglycerin (either as a sublingual tablet or spray) is an effective, convenient, and generally safe therapeutic option with multiple therapeutic benefits. Apart from its more typical role as an acute treatment for alleviating acute anginal episodes, it has well-recognized (but perhaps underappreciated) therapeutic benefits when used as a prophylactic intervention to prevent angina attacks that are known to be exertional, or when used acutely as an adjunctive treatment to reduce preload and elevated left ventricular filling pressures in patients with acute heart failure exacerbations. Health care professionals should remember to utilize shortacting nitrates as a prophylactic part of an exercise regimen, and to advise patients that the prophylactic administration of short-acting nitroglycerin may be extremely effective in preventing anginal episodes in patients whose symptoms are predictably exacerbated by exertion. Sublingual nitroglycerin should also be considered as an integral part of a hospital discharge medication regimen in order to reduce angina related re-admission rates. ${ }^{8}$ Short-acting nitrates are a pivotal, yet frequently overlooked component of OMT and should be integrated into secondary prevention measures, as has been convincingly demonstrated in several trials, including the COURAGE trial. ${ }^{54}$ Short-acting nitrates together with exercise therapy, and as part of a structured cardiac rehabilitation program, should also be considered a central component of secondary prevention in patients with chronic stable angina, which is likewise under-prescribed and under-utilized. ${ }^{7,8}$

A greater patient and provider understanding regarding the overall benefits of OMT, a more enlightened appreciation of the multiple roles of short-acting nitrate therapy in cardiovascular therapeutics, and a greater application of short-acting nitrates as part of a structured, regular exercise regimen to improve symptomatic outcomes and quality of life for patients with SIHD, is imperative to optimize both quality of life and enhanced functional status. ${ }^{8}$ While in the COURAGE trial, PCI combined with OMT was more effective in controlling angina than OMT alone for a finite time period (eg, the clinical benefit was modest and lasted only up to 1-2 years, depending on the quality of life metric chosen), this incremental benefit of PCI was not durable over a long follow-up period as compared with OMT alone. ${ }^{36}$ Although PCI with OMT mostly benefited patients with severe angina, OMT alone was likewise remarkably effective in treating most patients. In terms of economic burden, PCI when compared with OMT costs approximately US\$10,000 more per patient, without any significant gain in life-years or qualityadjusted life-years. Cost-effectiveness analysis showed that the per-patient cost required to derive significant angina improvement from PCI was approximately US\$150,000, 55,56 highlighting the importance of acknowledging the complementary roles of OMT and PCI. 


\section{Conclusion}

It is perhaps sobering to recognize that most health care providers use sublingual nitroglycerin based on guidelines solely for short-acting relief of acute angina. Their presumptive primary concern appears to be related to the development of nitrate tolerance and tachyphylaxis, and that patients will not receive a sustained therapeutic benefit from nitroglycerin. With increasing availability of PCI, patients and some providers also perceive medical therapy as less effective when compared with invasive procedures. In addition, some patients may become reluctant to embrace medical therapy because they tend to downregulate activity or exertion rather than use nitroglycerin as a preventive measure to alleviate angina. Patients should be made aware that nitrates can be used for symptom prophylaxis and to prevent symptomatic episodes of angina,${ }^{8}$ and that participation in a regular physical activity program is a safe, effective, and proven approach to effectively manage SIHD. Even a small increase in physical activity and regular exercise is likely to improve the overall health and promote longevity. ${ }^{57}$ To harness and optimize the concept of "exercise is medicine", providers will need to realize that currently too many patients with SIHD are not prescribed nitrate therapy as part of an overall management strategy that embraces both proven pharmacologic therapies as well as physical activity and comprehensive exercise programs, be they structured or home-based. ${ }^{8}$ In this context, the effectiveness and convenience of short-acting nitroglycerin (sublingual spray or tablet formulations) in treating and preventing angina attacks, and in improving the quality of life, can be realized if physicians and providers recognize the many therapeutic benefits of both a time-honored and often-overlooked medication that continues to play an important role in enhancing the treatment of patients with SIHD.

\section{Acknowledgment}

Medical writing services were provided by Cactus Communications, funded by an unrestricted educational grant from Arbor Pharmaceuticals. The authors retained full control of the manuscript content, editing, and final submission.

\section{Disclosure}

The authors report no conflicts of interest in this work.

\section{References}

1. Go AS, Mozaffarian D, Roger VL, et al; American Heart Association Statistics Committee and Stroke Statistics Subcommittee. Heart disease and stroke statistics - 2013 update: a report from the American Heart Association. Circulation. 2013;127(1):e6-e245.
2. Lerner DJ, Kannel WB. Patterns of coronary heart disease morbidity and mortality in the sexes: a 26-year follow-up of the Framingham population. Am Heart J. 1986;111(2):383-390.

3. Shaw LJ, Bairey Merz CN, Pepine CJ, et al; WISE Investigators. Insights from the NHLBI-Sponsored Women's Ischemia Syndrome Evaluation (WISE) Study: Part I: Gender differences in traditional and novel risk factors, symptom evaluation, and gender-optimized diagnostic strategies. J Am Coll Cardiol. 2006;47(3 Suppl):S4-S20.

4. Ferreira-Gonzalez I. The epidemiology of coronary heart disease. Rev Esp Cardiol. 2014;67(2):139-144.

5. Finegold JA, Asaria P, Francis DP. Mortality from ischaemic heart disease by country, region, and age: statistics from World Health Organisation and United Nations. Int J Cardiol. 2013;168(2):934-945.

6. Montalescot G, Sechtem U, Achenbach S, et al; Task Force Members; ESC Committee for Practice Guidelines. 2013 ESC guidelines on the management of stable coronary artery disease: The Task Force on the management of stable coronary artery disease of the European Society of Cardiology. Eur Heart J. 2013;34(38):2949-3003.

7. Fihn SD, Gardin JM, Abrams J, et al; American College of Cardiology Foundation/American Heart Association Task Force. 2012 ACCF/ AHA/ACP/AATS/PCNA/SCAI/STS Guideline for the diagnosis and management of patients with stable ischemic heart disease: a report of the American College of Cardiology Foundation/American Heart Association Task Force on Practice Guidelines, and the American College of Physicians, American Association for Thoracic Surgery, Preventive Cardiovascular Nurses Association, Society for Cardiovascular Angiography and Interventions, and Society of Thoracic Surgeons. Circulation. 2012;126(25):e354-e471.

8. Boden WE, Finn AV, Patel D, Peacock WF, Thadani U, Zimmerman FH. Nitrates as an integral part of optimal medical therapy and cardiac rehabilitation for stable angina: review of current concepts and therapeutics. Clin Cardiol. 2012;35(5):263-271.

9. Murrell W. Nitroglycerine as a remedy for angina pectoris. Lancet. 1879 $1: 80-81$.

10. Thadani U, Lipicky RJ. Short and long-acting oral nitrates for stable angina pectoris. Cardiovasc Drugs Ther. 1994;8(4):611-623.

11. Kimchi A, Lee G, Amsterdam E, Fujii K, Krieg P, Mason DT. Increased exercise tolerance after nitroglycerin oral spray: a new and effective therapeutic modality in angina pectoris. Circulation. 1983;67(1): $124-127$.

12. Kolenda K. Value of glyceryl trinitrate in exercise therapy. Prophylactic use in patients with coronary heart disease and stable angina pectoris. Fortschr Med. 1998;116:S65-S70.

13. Thadani U, Wittig T. A randomized, double-blind, placebo-controlled, crossover, dose-ranging multicenter study to determine the effect of sublingual nitroglycerin spray on exercise capacity in patients with chronic stable angina. Clin Med Insights Cardiol. 2012;6:87-95.

14. Thadani U. Oral nitrates: more than symptomatic therapy in coronary artery disease? Cardiovasc Drugs Ther. 1997;11 Suppl 1:213-218.

15. Lüscher TF. Endogenous and exogenous nitrates and their role in myocardial ischaemia. Br J Clin Pharmacol. 1992;34 Suppl 1:29S-35S.

16. Abrams J. The role of nitrates in coronary heart disease. Arch Intern Med. 1995;155(4):357-364.

17. Silber S. Nitrates: why and how should they be used today? Current status of the clinical usefulness of nitroglycerin, isosorbide dinitrate and isosorbide5-mononitrate. Eur J Clin Pharmacol. 1990;38 Suppl 1:S35-S51.

18. Fallen EL, Nahmias C, Scheffel A, Coates G, Beanlands R, Garnett ES. Redistribution of myocardial blood flow with topical nitroglycerin in patients with coronary artery disease. Circulation. 1995;91(5): 1381-1388.

19. Jugdutt BI, Becker LC, Hutchins GM, Bulkley BH, Reid PR, Kallman CH. Effect of intravenous nitroglycerin on collateral blood flow and infarct size in the conscious dog. Circulation. 1981;63(1):17-28.

20. Winbury MM, Howe BB, Weiss JR. Effect of nitroglycerin and dipyridamole on epicardial and endocardial oxygen tension - further evidence for redistribution of myocardial blood flow. J Pharmacol Exp Ther. 1971; 176(1):184-199. 
21. Fam WM, McGregor M. Effect of coronary vasodilator drugs on retrograde flow in areas of chronic myocardial ischemia. Circ Res. 1964; 15:355-364.

22. Fam WM, McGregor M. Effect of nitroglycerin and dipyridamole on regional coronary resistance. Circ Res. 1968;22(5):649-659.

23. Horwitz LD, Gorlin R, Taylor WJ, Kemp HG. Effects of nitroglycerin on regional myocardial blood flow in coronary artery disease. J Clin Invest. 1971;50(8):1578-1584.

24. Brown BG, Lee AB, Bolson EL, Dodge HT. Reflex constriction of significant coronary stenosis as a mechanism contributing to ischemic left ventricular dysfunction during isometric exercise. Circulation. 1984; $70(1): 18-24$.

25. Fujita M, Yamanishi K, Inoko M, Miwa K. Preferential dilation of recipient coronary arteries of the collateral circulation by intracoronary administration of nitroglycerin. J Am Coll Cardiol. 1994;24(3):631-635.

26. Cohn PF, Maddox D, Holman BL, et al. Effect of sublingually administered nitroglycerin on regional myocardial blood flow in patients with coronary artery disease. Am J Cardiol. 1977;39(5):672-678.

27. Loscalzo J. Antiplatelet and antithrombotic effects of organic nitrates. Am J Cardiol. 1992;70(8):18B-22B.

28. Diodati J, Théroux P, Latour JG, Lacoste L, Lam JY, Waters D. Effects of nitroglycerin at therapeutic doses on platelet aggregation in unstable angina pectoris and acute myocardial infarction. Am J Cardiol. 1990;66(7):683-688.

29. Buschmann M, Wiegand A, Schnellbacher K, et al. Comparison of the effects of two different galenical preparations of glyceryl trinitrate on pulmonary artery pressure and on the finger pulse curve. Eur J Clin Pharmacol. 1993;44(5):451-456.

30. Kuvin JT, Patel AR, Sidhu MS, et al. Relation between high-density lipoprotein cholesterol and peripheral vasomotor function. Am J Cardiol. 2003;92(3):275-279.

31. Kuvin JT, Sidhu MS, Patel AR, Sliney KA, Pandian NG, Karas R. Pulse pressure and peripheral arterial vasoreactivity. J Hum Hypertens. 2005;19(6):501-502.

32. Tadamura E, Mamede M, Kubo S, et al. The effect of nitroglycerin on myocardial blood flow in various segments characterized by restredistribution thallium SPECT. J Nucl Med. 2003;44(5):745-751.

33. Sakakura K, Nakano M, Otsuka F, Ladich E, Kolodgie FD, Virmani R. Pathophysiology of atherosclerosis plaque progression. Heart Lung Circ. 2013;22(6):399-411.

34. Thadani U, Parker JO. Influence of glyceryl trinitrate during supine and upright exercise in patients with angina pectoris. Br Heart J. 1978; 0(11):1229-1236.

35. Zimmerman FH, Boden WE. Stable Angina: Optimizing Therapies Old and New. New York: Medscape Education; 2011. Available at http://www. medscape.org/viewarticle/741441_transcript. Accessed April 15, 2014.

36. Boden WE, O'Rourke RA, Teo KK, et al; COURAGE Trial Research Group. Optimal medical therapy with or without PCI for stable coronary disease. N Engl J Med. 2007;356(15):1503-1516

37. Boden WE, O'Rourke RA, Teo KK, et al; COURAGE trial coprincipal investigators and study coordinators. Design and rationale of the Clinical Outcomes Utilizing Revascularization and Aggressive DruG Evaluation (COURAGE) trial Veterans Affairs Cooperative Studies Program no 424. Am Heart J. 2006;151(6):1173-1179.

38. Anderson JL, Adams CD, Antman EM, et al; Writing Group Members; ACCF/AHA Task Force Members. 2011 ACCF/AHA Focused Update Incorporated Into the ACC/AHA 2007 Guidelines for the Management of Patients With Unstable Angina/Non-ST-Elevation Myocardial Infarction: a report of the American College of Cardiology Foundation/ American Heart Association Task Force on Practice Guidelines. Circulation. 2011;123(18):e426-e579.

39. Johnson JM, Minson CT, Kellogg DL Jr. Cutaneous vasodilator and vasoconstrictor mechanisms in temperature regulation. Compr Physiol. 2014;4:33-89.

40. Wight LJ, VandenBurg MJ, Potter CE, Freeth CJ. A large scale comparative study in general practice with nitroglycerin spray and tablet formulations in elderly patients with angina pectoris. Eur J Clin Pharmacol. 1992;42(3):341-342.
41. Ducharme A, Dupuis J, McNicoll S, Harel F, Tardif JC. Comparison of nitroglycerin lingual spray and sublingual tablet on time of onset and duration of brachial artery vasodilation in normal subjects. $\mathrm{Am}$ J Cardiol. 1999;84(8):952-954.

42. Armstrong PW, Armstrong JA, Marks GS. Blood levels after sublingual nitroglycerin. Circulation. 1979;59(3):585-588.

43. Sato H, Koretsune Y, Taniguchi T, et al. Studies on the response of nitroglycerin oral spray compared with sublingual tablets for angina pectoris patients with dry mouth. A multicenter trial. Arzneimittelforschung. 1997;47(2):128-131.

44. Fox K, Garcia MA, Ardissino D, et al; Task Force on the Management of Stable Angina Pectoris of the European Society of Cardiology; ESC Committee for Practice Guidelines (CPG). Guidelines on the management of stable angina pectoris: executive summary: The Task Force on the Management of Stable Angina Pectoris of the European Society of Cardiology. Eur Heart J. 2006;27(11):1341-1381.

45. Vandenburg MJ, Wight LJ, Griffiths GK, Brandmann S. Sublingual nitroglycerin or spray in the treatment of angina. Br J Clin Pract. 1986;40(12): 524-527.

46. Olesen J, Iversen HK, Thomsen LL. Nitric oxide supersensitivity: a possible molecular mechanism of migraine pain. Neuroreport. 1993;4(8): 1027-1030.

47. Tfelt-Hansen PC, Tfelt-Hansen J. Nitroglycerin headache and nitroglycerin-induced primary headaches from 1846 and onwards: a historical overview and an update. Headache. 2009;49(3): 445-456.

48. Münzel T, Daiber A, Mülsch A. Explaining the phenomenon of nitrate tolerance. Circ Res. 2005;97(7):618-628.

49. New Zealand Medicines and Medical Devices Safety Authority. Nitrolingual $^{\circledR}$ Pumpspray Data Sheet (Glyceryl trinitrate $0.4 \mathrm{mg}$ / metered dose). Wellington: New Zealand Medicines and Medical Devices Safety Authority; 2012. Available from: http://www.medsafe. govt.nz/profs/datasheet/n/nitrolingualpumpspray.pdf. Accessed July 15, 2014

50. Hadjimiltiades S, Panidis IP, McAllister M, Ross J, Mintz GS. Dynamic changes in left ventricular outflow tract flow velocities after amyl nitrite inhalation in hypertrophic cardiomyopathy. Am Heart J. 1991;121:1143-1148.

51. Grose R, Nivatpumin T, Katz S, Yipintsoi T, Scheuer J. Mechanism of nitroglycerin effect in valvular aortic stenosis. Am J Cardiol. 1979; 44(7):1371-1377.

52. Tebbe U, Neuhaus KL, Sauer G, Neumann P, Kreuzer H. Nitrates in aortic valve disease: acute and chronic effects. Z Kardiol. 1983;72 Suppl 3: $152-155$.

53. Basta LL, Raines D, Najjar S, Kioschos JM. Clinical, haemodynamic, and coronary angiographic correlates of angina pectoris in patients with severe aortic valve disease. Br Heart J. 1975;37(2):150-157.

54. Maron DJ, Boden WE, Weintraub WS, Calfas KJ, O'Rourke RA. Is optimal medical therapy as used in the COURAGE Trial feasible for widespread use? Curr Treat Options Cardiovasc Med. 2011; 13(1):16-25.

55. Weintraub WS, Boden WE, Zhang Z, et al; Department of Veterans Affairs Cooperative Studies Program No. 424 (COURAGE Trial) Investigators and Study Coordinators. Cost-effectiveness of percutaneous coronary intervention in optimally treated stable coronary patients. Circ Cardiovasc Qual Outcomes. 2008;1(1):12-20.

56. Maron DJ. Using COURAGE to treat angina. Medscape J Med. 2008;10(12):286

57. Hambrecht R, Berra K, Calfas KJ. Cardiology patient page. Managing your angina symptoms with nitroglycerin: what about exercise? Circulation. 2013;127(22):e642-e645.

58. Aroney CN, Aylward P, Allen RM, et al; Acute Coronary Syndrome Guidelines Working Group. National Heart Foundation of Australia, Cardiac Society of Australia and New Zealand, Guidelines for the Management of Acute Coronary Syndromes 2006. Sydney: The Cardiac Society of Australia and New Zealand. Available from: http:// www.heartfoundation.org.au/SiteCollectionDocuments/mja-issue.pdf. Accessed January 9, 2014. 
59. National Institute for Health and Care Excellence. NICE Clinical Guideline 126. Management of Stable Angina. London: National Institute for Health and Clinical Excellence. Available from: http://www.nice. org.uk/guidance/cg126/chapter/Key-priorities-for-implementation. Accessed January 9, 2014.
60. Canadian Cardiovascular Society. Consensus Conference on the Evaluation and Management of Chronic Ischemic Heart Disease. Ottawa: Canadian Cardiovascular Society; 1997. Available from: http://www. ccs.ca/images/Guidelines/Guidelines_POS_Library/IHD_CC_1997. pdf. Accessed January 9, 2014. 


\section{Supplementary material}

Table SI Recommendations for nitroglycerin in various guidelines

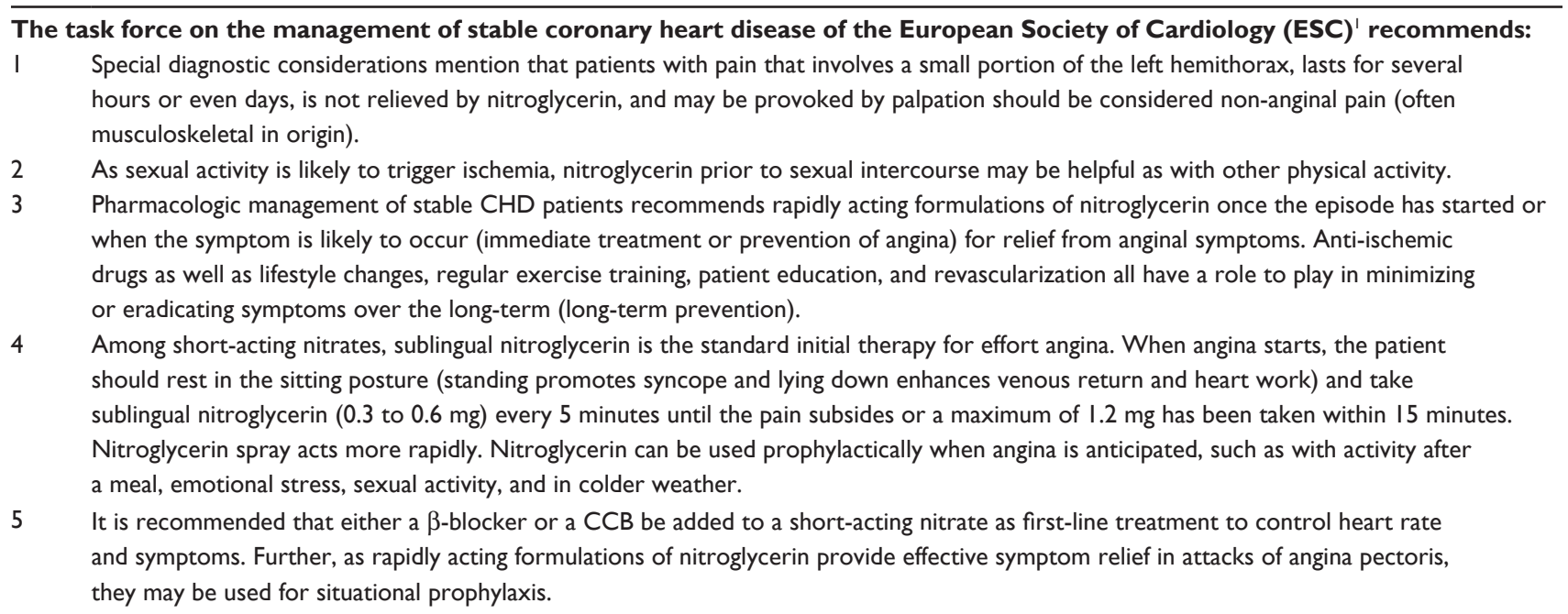

2012 ACCF/AHA/ACPIAATS/PCNA/SCAI/STS Guideline for the diagnosis and management of patients with stable ischemic heart disease. A Report of the American College of Cardiology Foundation/American Heart Association Task Force on Practice Guidelines, and the American College of Physicians, American Association for Thoracic Surgery, Preventive Cardiovascular Nurses Association, Society for Cardiovascular Angiography and Interventions, and Society of Thoracic Surgeons. ${ }^{2}$

I Sublingual nitroglycerin or nitroglycerin spray is recommended for immediate relief of angina in patients with SIHD. (Level of Evidence: B).

2 All patients with SIHD should be prescribed sublingual nitroglycerin tablets or nitroglycerin spray for immediate relief of angina. Most patients respond within 5 minutes of taking I to 2 sublingual dose(s) of 0.3 to $0.6 \mathrm{mg}$ each. Nitroglycerin spray is available in a $0.4 \mathrm{mg}$ metered-dose canister that dispenses 200 doses. The tablets should be placed under the tongue and not swallowed. If the spray is used, it should be applied to the tongue and not swallowed or inhaled. If additional doses are necessary, they should be taken at 5-minute intervals, for a maximum dose of $\leq 1.2 \mathrm{mg}$ within 15 minutes. During this timeframe, if relief does not occur, the patient should seek immediate medical attention. These formulations are also effective for prevention of effort-induced angina when administered 5 to 10 minutes before activity, with relief lasting approximately 30 to 40 minutes. The tablets must be kept in the manufacturer's bottle (loss of potency can occur in a few hours if out of the bottle) and should be stored in a cool, dry place; however, they should not be refrigerated. The tablets should not be used 6 to 12 months after opening the bottle due to potential decrease in efficacy and/or potency. Patients are usually able to detect when tablets have lost potency by the absence of a burning sensation beneath the tongue. Nitroglycerin ointment may also be used for short-term relief of angina.

3 Under Additional Medical Therapy to Prevent Ml and Death: Recommendations

The combination of a $\beta$-blocker with a nitrate could be an additive combination in patients with SIHD. However, abrupt $\beta$-blocker withdrawal should be avoided because heightened $\beta$-receptor density and sensitivity can result in a rebound phenomenon associated with an increased risk for acute $\mathrm{MI}$ and sudden death. If withdrawal is necessary, $\beta$-blockers should be tapered over a I- to 3-week period, with consideration given to use of sublingual nitroglycerin or substitution with a nondihydropyridine $C C B$ during the withdrawal period.

The 20 I I American College of Cardiology Foundation (ACCF)/AHA focused on an update incorporated into the ACC/AHA 2007 guidelines for the management of patients with unstable angina/non-ST-elevation myocardial infarction. ${ }^{3}$

I Patients with suspected acute coronary syndrome who have been prescribed nitroglycerin previously should initially take no more than one nitroglycerin dose sublingually in response to chest discomfort/pain. If no relief occurs, or if pain worsens 5 minutes after taking one nitroglycerin dose, the patient or family member/friend/caregiver should call 9-I-I immediately to access emergency medical services before taking additional nitroglycerin. In patients with chronic stable angina, if symptoms are significantly improved by one nitroglycerin dose, it is appropriate to instruct the patient or family member/friend/caregiver to repeat nitroglycerin every 5 minutes for a maximum of three doses, and call $9-\mathrm{I}-\mathrm{I}$ if symptoms have not resolved completely (Level of Evidence: $\mathrm{C}$ ).

2 While awaiting ambulance arrival, health care providers and 9-I-I dispatchers can advise patients who tolerate nitroglycerin to repeat nitroglycerin every 5 minutes for a maximum of three doses (Level of Evidence: $\mathrm{C}$ ).

3 Furthermore, if the symptoms subside within 5 minutes of when they began, patients should notify their physician of the episode. Patients with new-onset chest discomfort, who have not been prescribed nitroglycerin, should be discouraged from seeking nitroglycerin from others (neighbor, friend, or relative).

4 Recommendations for anti-ischemic therapy: Class I = patients with unstable angina or non-ST-elevation myocardial infarction (UA/NSTEMI) with ongoing ischemic discomfort should receive sublingual nitroglycerin $(0.4 \mathrm{mg})$ every 5 minutes for a total of three doses. Thereafter, these patients should be assessed for the need of intravenous nitroglycerin, unless contraindicated (Level of Evidence: C). 
Table SI (Continued)

Class I = low-risk patients referred for outpatient stress testing should receive appropriate precautionary pharmacotherapy

(eg, acetylsalicylic acid, sublingual nitroglycerin, and/or $\beta$-blockers) while awaiting results of the stress test (Level of Evidence: $C$ ).

6 Class I = all post-UA/NSTEMI patients should receive a prescription for sublingual or nitroglycerin spray and instructions for its use (Level of Evidence: C).

Abbreviations: AATS, American Association for Thoracic Surgery; ACCF, American College of Cardiology Foundation; AHA, American Heart Association; ACP, American College of Physicians; PCNA, Preventive Cardiovascular Nurses Association; SCAI, Society for Cardiovascular Angiography and Interventions; STS, Society of Thoracic Surgeons; CCB, calcium channel blocker; CHD, coronary heart disease; MI, myocardial infarction; SIHD, stable ischemic heart disease; UA, unstable angina; NSTEMI, nonST-elevation myocardial infarction.

\section{References}

1. Montalescot G, Sechtem U, Achenbach S, et al. 2013 ESC guidelines on the management of stable coronary artery disease: The Task Force on the management of stable coronary artery disease of the European Society of Cardiology. Eur Heart J. 2013;34(38):2949-3003.

2. Fihn SD, Gardin JM, Abrams J, et al; American College of Cardiology Foundation/American Heart Association Task Force. 2012 ACCF/ AHA/ACP/AATS/PCNA/SCAI/STS Guideline for the diagnosis and management of patients with stable ischemic heart disease: a report of the American College of Cardiology Foundation/American Heart Association Task Force on Practice Guidelines, and the American College of Physicians, American Association for Thoracic Surgery, Preventive Cardiovascular Nurses Association, Society for Cardiovascular Angiography and Interventions, and Society of Thoracic Surgeons. Circulation. 2012;126(25):e354-e471.
3. Anderson JL, Adams CD, Antman EM, et al; Writing Group Members; ACCF/AHA Task Force Members. 2011 ACCF/AHA Focused Update Incorporated Into the ACC/AHA 2007 Guidelines for the Management of Patients With Unstable Angina/Non-ST-Elevation Myocardial Infarction: a report of the American College of Cardiology Foundation/American Heart Association Task Force on Practice Guidelines. Circulation. 2011;123(18):e426-e579.

\section{Publish your work in this journal}

Drug Design, Development and Therapy is an international, peerreviewed open-access journal that spans the spectrum of drug design and development through to clinical applications. Clinical outcomes, patient safety, and programs for the development and effective, safe, and sustained use of medicines are a feature of the journal, which has also been accepted for indexing on PubMed Central. The manuscript management system is completely online and includes a very quick and fair peer-review system, which is all easy to use. Visit http://www.dovepress.com/testimonials.php to read real quotes from published authors.

Submit your manuscript here: http://www.dovepress.com/drug-design-development-and-therapy-journal 